\title{
Risk and Opportunity Analysis of Tesla Motors Inc. Marketing Strategy and Business Ethics Study
}

\section{-- A Mini Review}

\author{
Fan Mo ${ }^{1, a,{ }^{*}}$, Yingying Wang ${ }^{2, b}$ \\ 1. Lee Shau Kee School of Business and Administration, The Open University of Hong Kong, \\ 518031, China \\ 2. School of Business \& Management, Management Development Institute of Singapore, 148951, \\ Singapore \\ a, *1220833480@qq.com, b124741383@qq.com
}

\begin{abstract}
Winning the Top 500 World Brands in 2018, Tesla is working hard to cover a variety of categories including high-end sports cars and luxury cars. As a leader in the "new car movement", Tesla from Silicon Valley is committed to building cars with IT concepts, and it is not a traditional car manufacturer's thinking represented by Detroit. This paper undertakes a full marketing audit to evaluate Tesla's strengths, weaknesses, opportunities and threats to many other car manufacturers using PEST, SWOT and USP models. Based on the above issues, the business process of external supply chain management is proposed: information-technology outreach, upstream management of docking, overall coordination and co-existence, and analysis of node elements and evaluation schemes are feasible. Besides, the recent accidents regarding the brake caliper bolts failure, battery charging, and pilot driving are also mentioned in this review. Corresponding recommendations are also provided for the improvement of moral images in the end.
\end{abstract}

Keywords: Eurasia; Russia; The United States; Geopolitical.

\section{Introduction}

Tesla, an American electric vehicle and energy company, mainly sells electric vehicles, solar panels and energy storage devices. In the past several years, due to the manufacturing problems of parts in Tesla factory, Tesla voluntarily recalled a number of designated models. It was founded in 2003 and is headquartered in Silicon Valley, California, USA. Palo Alto; the CEO is Elon Musk, known as "Silicon Valley Iron Man," and joined the company in 2004 [1-2]. The company is named after electrical physicist Tesla, and produces and sells electric vehicles, solar panels, and energy storage equipment. It is the first electric vehicle company in the world to use lithium-ion batteries: Tesla Roadster, Tesla Model S, Tesla are now available Model X and other major models. In this paper, full marketing analysis of Tesla's strengths, weaknesses, opportunities and risk and opportunity using PEST, SWOT and USP models. Besides, its unique IT branding and marketing objectives to increase brand awareness, market share, sales are included also in the discussions.

\section{Tesla's Corporate Strategy Analysis via Different Models}

\subsection{PESTLE Analysis of Tesla's Corporate Strategy}

Political Env. Analysis

In recent years, with the continuous deterioration of the human living environment, the international community has jointly realized that the emission of automobile exhaust is an important factor leading to this result, in view of this, the U.S. government plans to invest $\$ 7.5$ billion in the development of electric vehicles by 2019, Tesla Motors is growing up in such a political environment [3]. 
Volume 13 (2021)

\section{Economic Env. Analysis}

Traditional economy is in the doldrums and the new economy such as internet, new energy and electric vehicles are developing rapidly. Tesla Motors has followed this trend and developed into a group of dark horses in this industry [4]. Various countries have introduced generous policy treatment about electric vehicles, e.g., low-interest loans, policy subsidies, etc.

Social Env. Analysis

As a new high-tech fashion car, Tesla car attracted a large number of people's attention at the beginning of its birth, which greatly stimulated the demand for electric car consumption and the presale period was extremely hot [5]. With the improvement of people's living standard, the recognition of environmental protection and high-tech concept is deepening.

\section{Technical Env. Analysis}

The advanced battery management system, Tesla's battery pack is integrated into a flat plate placed on the floor, thus ensuring his range and good manoeuvrability; the differential pressure variable speed technology of the transmission system makes the Tesla car can instantly accelerate and instantly brake, thus ensuring the safety of the car [6].

Legal Factors Impacts

Defective product claims, patent \& copyrights laws are the main factors that may cause impact to the company, i.e., the Autopilot mode of Tesla has caused some accidents, and many people have raised the question about the company's technology [7]. And the design, technology, and uniqueness are very important for the growth and profitability of Tesla.

\section{Env. Factors Impacts}

Tesla has significant advantages over car manufacturers. Fuel efficiency and environmental friendliness are the two major advantages of Tesla Motors that the brand has over competitors. Most importantly, it doesn't emit carbon into the atmosphere and cause pollution [8]. But still the generation of the electricity still needs the burning of the petrol or diesel, which might expose 2nd pollution to the environment. To sum up, all the relative discussion are all listed in Fig. 1.

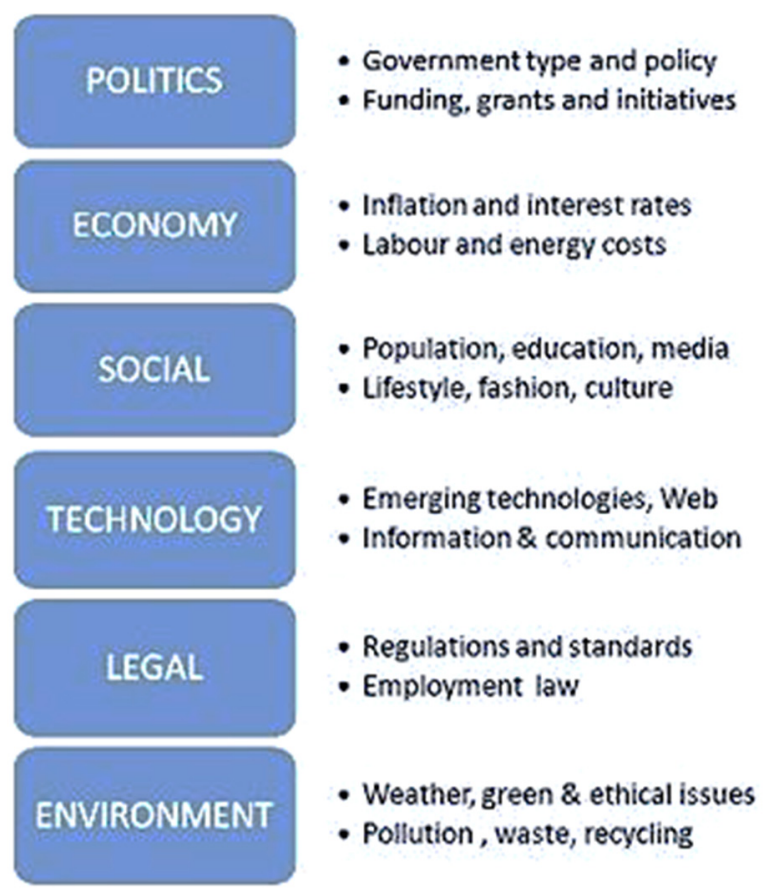

Figure 1. PESTEL analysis of Tesla Motors Inc. [3]

\subsection{SWOT Analysis of Tesla's Corporate Strategy}

The Tesla SWOT analysis reveals that the biggest challenges come from competitive threats within the automotive industry. In the SWOT analysis of Tesla in Fig. 2, the strengths and weaknesses of 
Tesla as well some of the threats and opportunities it faces are indicated and analysed accordingly [9].

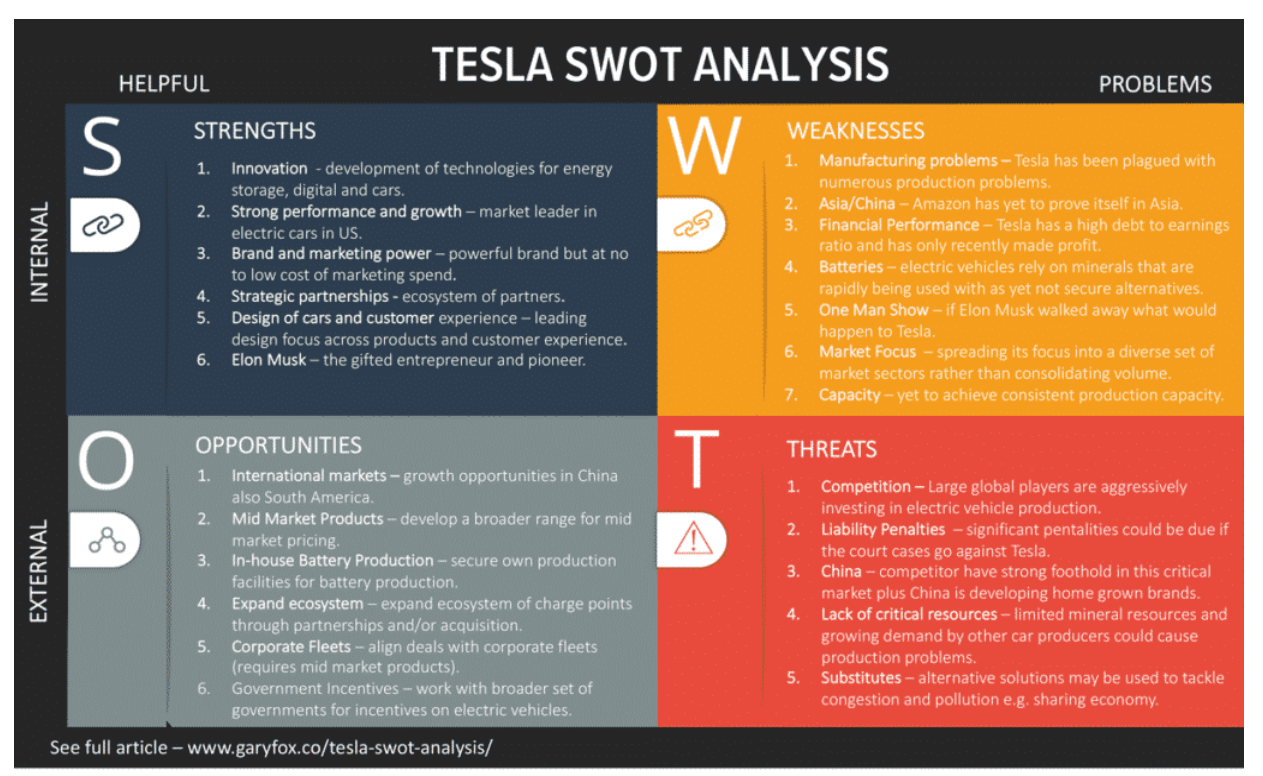

Figure 2. SWOT analysis of Tesla Motors Inc. [10]

\section{Advantages}

Tesla has a complete industry chain, for example, in California, Tesla has built hundreds of charging stations, so that the charging bottleneck of electric cars can be solved; Tesla has removed the internal combustion engine module compared with traditional cars, so it has more space in the body and can put luggage in the front and back [11]. Tesla has three power versions and three charging methods, so that customers can have different experiences; Tesla cars have luxurious configurations, which are no less than Mercedes-Benz and BMW.

Disadvantages

The disadvantages of Tesla cars are also the disadvantages of the whole electric car industry, mainly in two aspects, one is that the profitability of Tesla cars is very risky, compared with traditional cars, it has less ability to bear the risk, if the demand for electric cars fluctuates slightly, or production delay happens, Tesla may suffer a big risk; the other is also the most important point is the safety of the battery [6,12]. Another point is the safety of the battery. In November 2013, Tesla's consecutive fire accidents made its market value evaporate nearly $28 \%$. Although its battery has certain advantages over other electric cars, it is far from the public standard [12-13].

Opportunities

The third phase of Tesla's factory project is to establish an automated factory with an annual production capacity of one million, so that the benefits of electric vehicles can benefit the general public. Tesla's models are completely based on the characteristics of electric drive and design, its superior SUV driving experience are currently experiencing strong market demand in the Chinese and European markets.

Threat

Although Tesla's battery management system and differential pressure transmission technology for the drivetrain are industry-leading, other companies are acquiring this technology, and it is conceivable that once other companies acquire this technology. If Tesla fails to develop a more effective technology, then the future of Tesla will become murky. The hybrid electric car and fuel cell car will enter the public's view more quickly, and the fuel cell truly has zero emissions and a longer range [13]. 


\subsection{Porter's Five Forces Analysis of Tesla's Corporate Strategy}

The below Five Forces Analysis are applied to define the potential competitive strategy of Tesla. And below is the detailed analysis for each portion.

Entry of New Entrant

The threat level of new entrants is relatively low, which is manifested in the following aspects. As a new industry, the technical requirements of electric vehicles are quite high, if there is no certain technology, there is still a certain air difficulty to enter the electric vehicle industry. The manufacturing cost of electric vehicles is high and requires considerable financial support [2,7].

Alternative Products or Services

First, from the perspective of environmental protection and energy utilization, hybrid cars and fuel cell electric vehicles are their main alternatives [6]. Hybrid cars have been developed for a long time, the technology is more mature, stable, safe, with high market awareness, but there is not much room for automotive innovation [14].

Customer Bargaining Power

Standing in the perspective of electric vehicles, the bargaining power of customers for cars is relatively weak, mainly because of the following reasons. The group of people who buy electric cars is a specific group of people, these people are either rich or noble, and they focus on things other than money, such as the experience of the car, fascination with new technology, or even to be new and different [15]. Fewer competitors for pure EVs and lack of reference for customers to buy them lead to unilateral pricing by EV companies.

Bargaining Power of Suppliers

The bargaining power of suppliers is weak from a comprehensive perspective, mainly in the following aspects. (i) The traditional automobile industry has been developed for a long time, each supply chain link tends to be mature, the market mechanism is more perfect, each manufacturer competes fairly, and there is no monopoly in technology. (ii) Core technology, such as battery management system is manufactured by Tesla itself, compared with other companies, Tesla has a certain technical advantage, there is no bargaining power of suppliers this link [5,16-17].

Existing Competition in the Industry

At present, there are few manufacturers of pure electric vehicles, the market is in the development stage, not fully exploited [9]. Power batteries have also been highly valued, and R\&D investment has increased sharply, and the expectation of breakthroughs in electric vehicle technology bottlenecks has been greatly enhanced, making the pace of the electric vehicle industry greatly accelerated, and as a sunrise product. The competition is continuously strengthening [18].

\section{Evaluation of Current Marketing Strategy}

\subsection{Existing Markets for Existing Products (Market Penetration)}

From top to bottom, the decisions of a few people often determine the choices of the majority. In this form of organization, the people below often give up their choices in order to cater to the preferences or needs of the people above [19]. Bottom-up innovation is grassroots innovation, which is conducive to the creativity of everyone and each economic subject, and the energy generated by innovation is far greater than that of top-down innovation.

\subsection{Cost-down Strategy}

Sales: Continue to promote the direct sales model, open experience stores and promote online ordering, in today's social environment, experience seems to have become the most important part of the commodity economy. So, the opening of experience stores and the implementation of online ordering is imperative.

Promotion: deepen the self-media and social marketing. 
Information construction: strengthen internal management and external supply chain management, improve the level of enterprise information technology. In today's rapid development of business intelligence and CRM and SCM, the ability to ride on the modern high-speed train of informationization will directly affect the cost of the enterprise [20].

Manufacturing: Although Tesla Motors has basically achieved automated production in the manufacturing process, it still does not do well in some aspects, so it can achieve more efficient automated production through technological innovation and reduce costs.

\subsection{Product Differentiation Strategies}

Softening: Continue to develop its strengths and stay ahead of the industry. Putting the company's second focus on automotive software, with talks underway with Apple, if the company ever achieves this software breakthrough, Tesla's electric cars will be more competitive with other competing companies [21].

Smart: Like Apple, change the definition of car, let the car become a mobile terminal, personalized office, and life essential tools. Once such a vision becomes reality, then the subversion will not only be the modern definition of the car, and many industries will also be completely subverted.

Informatization: Like Google, provide timely, professional and effective information.

Diversification: Produce cabs, buses, etc. to meet the diverse needs of the market.

\section{Tesla's Information-Technology based Targeting \& Positioning}

\subsection{Enterprise Resource Planning (ERP)}

Enterprise Resource Planning (ERP) systems in the traditional sense cannot meet the needs of Tesla's current development, especially since Tesla has very high requirements for R\&D speed and agile development, and existing products in the market cannot meet these requirements. Although SAP's products can be used in other automotive industries, they are not applicable to Tesla [22]. Tesla has spent four months building their own ERP environment, and today this system is the basic platform for Tesla's efficient internal operations. The system ensures that resources can be shared and exchanged before each department.

\subsection{Car in Cloud: Cloud Computing and Big Data}

Tesla has always been enthusiastically sought after. In addition to super clean energy technology, large car space, and marketing experience like Apple 's mobile phone, cloud computing and big data platforms allow every car to be integrated into the Internet family, and driving is no longer dull, entering the era of smart cars-built on cloud computing and big data platforms, giving Tesla a stronger "heart" [23]. There are three afflictions in the Tesla big data system:

(i) Data definition capabilities, which specify structure of content of database.

(ii) Data dictionary, which automated or manual file storing definitions of data elements and their characteristics.

(iii) Querying and reporting: which is composed by data manipulation language and structured query language (SQL) and Report generation. As for Tesla's Cloud Computing Continues to Disrupt Company's Business Models, many decision makers find themselves wondering just that, as they try to decide where to take their cloud investments [24].

In this Cloud computing is an integral part of Tesla's overall strategy. The owner can adjust and control driving modes, entertainment systems, air conditioning, seat heating, sunroof The luggage compartment switch, charging settings, main power switch, etc. with simple touch, cooperation with local operators also makes it easy to access the Internet through $4 \mathrm{G}$, and supports mobile phone apps for basic vehicle control. Smart cars, autonomous driving, and connected cars are flourishing on cloud computing platforms [25]. For Tesla users, they can have a safer driving and more personalized experience: based on the cloud platform, the human-machine interaction in the center console is very streamlined, the touch screen only needs instructions Inputs and results are presented, and many 
functions provided by traditional in-vehicle hardware can be transferred to the cloud for processing, and related data can also be stored directly in the cloud; the savings in hardware also bring about a reduction in overall vehicle costs. In Tesla, the use of cloud computing technology can quickly set up a virtual development and test environment in the cloud. Once new functions and services are developed and tested, they can also be directly pushed to the user through the cloud. On the other hand, the vehicle actually runs various types of data generated in the system can be backed up as a basis for remote fault diagnosis $[19,26]$. Cloud storage and big data analysis capabilities greatly reduce costs and reduce risks caused by data loss. Moreover, customer data analysis and sales opportunity management in the cloud enable Tesla to further analyse and match customer needs, thereby continuously upgrading accurate digital marketing.

\subsection{Internet Thinking under Industry 4.0}

What makes Tesla so admirable is that it has not only changed the powertrain of the car, it is far more intelligent than people understand about cars. Tesla has to some extent matched the idea of Industry 4.0 by positioning itself at its core not as an electric car, but as a large intelligent terminal with the shape of a car. Firstly, it can be personalised: the Model S model on Tesla's Chinese website currently comes in seven body colours for customers to choose from; customers can also customise the roof and interior; another customisation needs such as adding a child seat in the boot are also possible [25]. Secondly, the car's 17-inch touchscreen centre console completely replaces the traditional car's centre console, allowing not only map navigation, multimedia control, website access and many other functions, but also the ability to control the car's heated seats, sunroof switch and other operations. In addition, Tesla's manufacturing is carried out at its 'Super Factory' in Northern California, USA, where almost the entire process from raw material to finished product is carried out, with the entire manufacturing process being automated to the extreme [26].

\subsection{Unusual Tesla IT Branding Strategy}

Elon Musk has not only given the Tesla electric car a distinctive look and core, but has also adopted a different marketing strategy. The marketing model used by Tesla is direct sales. While the traditional car marketing model is to open a $4 \mathrm{~S}$ shop, trade and pick up the car in a physical shop, Tesla has abandoned the car dealership step and adopted the Internet O2O direct sales model: offline experience, online booking and payment, eliminating the intermediary channel costs for customers to buy. It must be said that this was a disruptive model of selling cars before [27]. Since establishing its first direct shop in the US in 2008, Tesla has continued to develop its business through an overseas strategy and by building its own direct shops. Tesla builds high-tech showrooms around the world, like the Apple Experience, often in high-end shopping malls or in "strategic locations" in cities. As a result, every time a curious crowd passes by the showroom, they pull out their mobile phones and take pictures, which they share on social networks, leaving the rest of the marketing to the curious media and the internet [28-29]. In February 2019, Musk announced that it would open all Tesla electric vehicle patents, which is considered a feat of creating an industry ecology: an open big data platform allows third-party services to be accessed and can be greatly improved Industry ecosystem to provide customers with better applications and services [30-31].

All such big data platform is all rely on the big database, which is a big collection of related files containing records on people, places, or things. And such data base is prior to digital databases, business used file cabinets with paper files. Of course, such system also needs generalized category representing person, place, thing on which we store and maintain information to add in their data accordingly. An effective information system could provide all users in Tesla with accurate information and timely information, if it is available when it's needed to users or directors. This relevant information might be useful and appropriate information for the types of work and all decisions that require it. Such database that stores current and historical data that may be of interest to decision makers. Tesla should consider giving full play to the role of nodes in direct-operated stores in various places, actively absorbing feedback, Prompt delivery and maintenance. Although Tesla 
provides direct sales services through the Internet and removes dealers in terms of sales methods, vehicle maintenance still requires physical teams to complete operations that cannot be performed remotely; therefore, "direct stores" established everywhere can serve as maintenance mobility [32]. The team 's station, rental car or even a car resale physical platform will require a powerful and accurate real-time data system.

Second, Tesla is trying to build and improve infrastructure based on big data in application scenarios. Such as promoting the construction of interconnected charging piles, parking lots and even houses, laying a foundation for the future construction of energy and service sharing platforms [12,3334]. The goal of the strategy is to create a large self-regulating network that will change the energy use pattern with the interconnection of cars and homes, which is also in line with Musk's positioning for itself-far beyond the scope of automobile manufacturing. From a global perspective, the big data platform will integrate software and hardware, greatly expanding the imagination space, and making the automotive industry a platform covering multiple fields such as travel, energy, collaborative economy, and financing.

\section{Tesla's Recent Incidents and Recommendations}

In the past several years, due to the manufacturing problems of parts in Tesla factory, Tesla voluntarily recalled a number of designated models. News Link: "In 2021, Electric car maker Tesla (TSLA) announced new recalls some products in the United States. Tesla is recalling 5,974 of its electric vehicles over concerns that their brake caliper bolts might loosen, which could potentially cause a loss of tire pressure and increase the risk of a crash, according to documents made public by the National Highway Traffic Safety Administration. Cars that are part of the voluntary recall include certain 2019-2021 Model 3 vehicles and 2020-2021 Model Y vehicles. Tesla said it is not aware of any crash or injury resulting from the potential defect. It will inspect and tighten or replace the caliper bolts as necessary for free."

\subsection{Tesla Should Provide Consumers with Free Repair Services and Give Consumers Certain Economic Subsidies and Preferential Policies for Purchasing Other Products and Services}

From the perspective of consumers, more and more consumers (especially young consumers) believe that enterprises have the responsibility to abide by ethics and solve social and environmental problems. Tesla's product recalls this time is mainly due to the safety problems of products. The safety problems of vehicles will infringe on the life and safety rights of consumers to a certain extent. Major vehicle accidents may affect people's health and life rights. The right to life is a part of human rights and an inherent right of all people. Therefore, based on the theory of right based ethics, product safety is immoral to consumers $[13,17]$. In view of the current situation, it is Tesla's moral obligation as a manufacturer to provide consumers with free repair service. For consumers, free maintenance and replacement of parts is a good performance for enterprises to actively undertake and face social responsibility and enterprise problems. Through better service attitude and service quality, consumers' negative emotions towards Tesla can be improved, to reduce the loss of target customers and market share. At the same time, Tesla should also compensate consumers for other losses caused by product recall $[18,20]$. By giving consumers some subsidies for other services, we can make up for the inconvenience in daily travel caused by the car recall. This move will help to gain better recognition from consumers, to restore the company's moral image more quickly [24]. Actively admit the fault of the enterprise and give consumers free maintenance and compensation services, which shows the moral image of the enterprise and the response ability of the enterprise in the face of problems for both the market and the consumer groups. Therefore, by solving this product safety incident, Tesla can provide richer product experience and show a more positive corporate moral image for its future development. 


\subsection{Tesla Should Provide Protective Investment Policies for its Investors to Help Them Reduce the Losses Caused by this Incident}

Through the product recall of Tesla, it is exposed that there are some potential safety hazards in some Tesla vehicles. Due to the company's product problems and the influence of public opinion, Tesla's value in the market is subject to fluctuations. This has caused great economic loss for Tesla investors. Economic interests are the moral rights of investors. Consequence-based (utilitarianism) ethical theory is monism [12], because it puts forward a supreme principle (utilitarian principle) as the principle governing all moral problems, it advocates the policy of providing the greatest benefits and impartially considers everyone's interests. Therefore, from the perspective of consequence-based (utilitarianism) ethical theory, Tesla's product recall is immoral to investors. Judging from the current situation, Tesla's protective investment policy for investors is Tesla's practice of actively fulfilling its moral obligation. As a large company in the market, Tesla has the obligation to provide investors with appropriate investment protection and stop loss strategy. This kind of policy can reduce the investment risk of investors and increase the trust and favour of investors to Tesla brand. For investors, Tesla's corresponding investment protection policy and stop loss strategy can effectively reduce the direct loss of this event to investors' economic interests. Therefore, it helps Tesla improve its moral image in the hearts of investors. Tesla's initiative to take and protect investors' risks will undoubtedly have a positive moral impact on investors. For investors in the market, Tesla's investment risk protection measures will more easily win the favour of investors, which is more conducive to attract the attention of more other investors. For Tesla, the increase of investors will help the company attract more investment in the future, thus promoting the develop of the company in the future.

\subsection{Tesla Should Strengthen its Advertising and Use Social Media to Introduce the Company's Activities to Actively Fulfil its Moral Obligations}

The product recall has a serious negative impact on Tesla's moral image. The hidden danger of vehicle safety is mainly due to the unethical behavior caused by the negligence of Tesla's own production process. Therefore, improving Tesla's image in the public mind is very important for the overall development of the company. In my opinion, advertising is a very good way to Change the company's moral image. Advertising ethics is traditionally considered a normative process, defined as what ought to be done. So, in my opinion. Tesla should respond to this recall incident in accordance with the norms of advertising ethics. In response to this incident, Tesla company can issue a statement through social media to apologize and make compensation policies and use social media advertising to increase the company's publicity activities to deal with unethical behaviors, to reduce the negative impact of this product recall on the company's moral impression in society. Tesla should actively abide by the commercial ethics of advertising while using advertising. Based on advertising ethics, the main function of advertising is to persuade potential customers to buy the company's products. Therefore, Tesla needs to explain the advantages of the product in the advertisement and make a good explanation for the product recall. Only in this way can we maintain the brand loyalty of target consumers to Tesla. The use of social media and advertising to state and promise the event will help Tesla reduce and improve the negative impact of the event on consumers, investors and the company's own negative image. The improvement of the company's image will better promote the operation of the company, which can better mobilize the work enthusiasm of the employees in the company. The promotion of employees' enthusiasm and the restoration of the company's image are very favourable factors for Tesla's future development.

\section{Conclusion}

This article analyses the strengths, weaknesses, opportunities and risk and opportunity of Tesla Motor Inc. using PEST, SWOT and USP models. Besides, its unique information-technology branding and marketing objectives to increase brand awareness, market share, sales are included also in the discussions. It briefly describes the background of Tesla's company, describes in depth its 
industry initiatives of "designing and manufacturing cars with the technology concept, marketing branding, and its strengthening external supply chain management with information-technology systems. Tesla will become a vertically integrated energy company capable of providing end-to-end clean energy products. We look forward to Tesla continuing to move forward with its mission to accelerate the world's transition to sustainable energy" and hope it may succeed soon.

\section{Acknowledgments}

This work has been supported by Asia Education Institution (SG) since 2020, Project number: AEI201227G.

\section{References}

[1] Han Chaston, I. (2016). The Tesla / Ian Chaston. SAGE.

[2] Tesla, Inc. (2020). In Hoover's Company Records. Mergent.

[3] Hardman, S., Shiu, E., \& Steinberger-Wilckens, R. (2015).

[4] Changing the fate of Fuel Cell Vehicles: Can lessons be learnt from Tesla Motors? International Journal of Hydrogen Energy, 40(4), 1625-1638.

[5] Irwin, J. (2016). Tesla exec criticizes Michigan, EV rivals. Automotive News, 23(3), S022-.

[6] Jr, V. (2019). Sedan is still top choice among minority buyers; Tesla Model 3 is No. 1 registered by Asians. Automotive News, 94(6903), 4-.

[7] David Undercoffler. (2016). Imitating Tesla will be tough; Direct-sales model faces state barriers. Automotive News, 90(6745), 1-.

[8] Nelson, G. (2015). Battle of the brands; TESLA. Automotive News, 89(6654), 020-.

[9] Katie Burke. (2017). Ambitious, well-funded Volvo turns up the heat on Tesla; Swedish brand threatens the U.S. upstart's status as the king of cool EVs. Automotive News, 92(6804), 4-.

[10] Tesla SWOT Analysis - A SEXY Car Range but What's Missing, www.garyfox.co/tesla-swot-analysis/.

[11] Garrett Hering. (2020). Replacing gas, Strata Solar picks Tesla for Southern California battery Peaker. SNL Energy Power Daily.

[12] Elon Musk deletes Tesla and SpaceX from Facebook: Harsh reality check for Social Media Marketing; - Delivered by Feed43 service. (2018). AutoParts Asia.

[13] Charlsy Panzino. (2020). EV startups eyeing Tesla's success add competition to growing market. SNL Energy Power Daily.

[14] Chappell, L. (2010). Tesla stores: No dealers, no service. Automotive News, 84(6422), $23-$.

[15] Jason Stein. (2020). Q\&A: MUSK; Tesla CEO outlines manufacturing domination through efficiency. Automotive News, 94(6945), 10-.

[16] Proactive investors. (2020). Proactive Investors: Tesla Inc: Will Plaid be in fashion for 2021? In Newstex Finance \& Accounting Blogs. Newstex.

[17] Rechtin, M. (2012). Tesla line is rolling; real test begins; EVs must go beyond early adopters to broader market. Automotive News, 86(6523), 4-.

[18] Lauren Dixon. (2017). For innovation ideas, Tesla a model company to emulate. Rochester Business Journal, 33(13), 14-.

[19] Tesla Inc Annual Shareholders Meeting and Battery Day - Final. (2020). In Fair Disclosure Wire. CQRoll Call, Inc.

[20] Auto News Digest. (2010). Automotive News, 84(6421), 8-.

[21] Woodyard, C. (2015). Tesla starts selling used cars on its site. USA Today (Arlington, Va.), 03-.

[22] Tesla Led the Charge, But More Premium Electric Vehicles Are Arriving. (2019). In Weekend All Things Considered. National Public Radio, Inc. (NPR). 
Volume 13 (2021)

[23] Dawn Van Zant. (2020). InvestorIdeas.com: Cleantech and Climate Change Podcast: EV Industry Charging Ahead, Tesla Stock splits and XPeng Inc. Starts Trading following IPO. In Newstex Trade \& Industry Blogs. Newstex.

[24] Sunil Singh. (2018). Is there something wrong with Tesla? Gulf Marketing Review.

[25] Electric Vehicle Manufacturer Mullen Technologies, Inc. Gearing Up to Compete with Tesla and Faraday Future with Expanding Group of Experts. (2016). In Marketing Weekly News (p. 431-). NewsRX LLC.

[26] Tesla vs. Christie; Entrepreneur's daring meets political power. (2014). Telegram \& Gazette.

[27] Martinez, M. (2019). Troubled Tesla hopes Y will be the answer; Big potential, heavy burden, long wait for small crossover. Automotive News, 93(6873), 3-.

[28] Brian Albright. (2014). TESLA KEEPS FIGHTING. Aftermarket Business World, 123(1), 20-.

[29] Woodyard, C., Snavely, B., \& Bomey, N. (2013). Tesla shares sizzle on hot profit and hotter review. USA Today (Arlington, Va.), 05-.

[30] Pete Bigelow. (2020). Tesla's plan for Level 5 not feasible, experts say; Autonomy challenges, lack of technology cited. Automotive News, 94(6943), 3-.

[31] Bunkley, N. (2016). Can Chevy capitalize on Bolt's head start? GM's EV has advantages but lacks Tesla's cachet. Automotive News, 90(6744), 1-.

[32] Thomas, V., \& Maine, E. (2019). Market entry strategies for electric vehicle start-ups in the automotive industry - Lessons from Tesla Motors. Journal of Cleaner Production, 235, 653-663.

[33] Katie Burke. (2017). Volvo plans to change thinking about EVs; Will strategy help attract potential Tesla customers? Automotive News, 92(6792), 20-.

[34] Gardener, A., \& Jezzard, P. (2015). Investigating white matter perfusion using optimal sampling strategy arterial spin labeling at 7 Tesla. Magnetic Resonance in Medicine, 73(6), 2243-2248. 